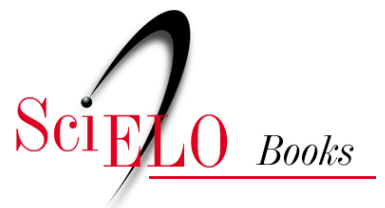

\title{
EDUFU
}

\section{John Dewey \\ o lugar da Educação na sociedade democrática}

Christiane Coutheux Trindade

\section{SciELO Books / SciELO Livros / SciELO Libros}

TRINDADE, C.C. John Dewey: o lugar da Educação na sociedade democrática. In: BOTO, C., ed. Clássicos do pensamento pedagógico: olhares entrecruzados [online]. Uberlândia: EDUFU, 2019, pp. 115-140. História, Pensamento, Educação collection. Novas Investigações series, vol. 9. ISBN: 978-65-5824-027-3. Available from: http://books.scielo.org/id/fjnhs/pdf/boto-9786558240273-07.pdf. https://doi.org/10.14393/edufu-978-85-7078-472-8.

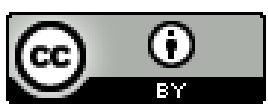

All the contents of this work, except where otherwise noted, is licensed under a Creative Commons Attribution 4.0 International license.

Todo o conteúdo deste trabalho, exceto quando houver ressalva, é publicado sob a licença Creative Commons Atribição 4.0.

Todo el contenido de esta obra, excepto donde se indique lo contrario, está bajo licencia de la licencia Creative Commons Reconocimento 4.0. 


\title{
John Dewey: o lugar da Educação na sociedade democrática ${ }^{1}$
}

\author{
Christiane Coutheux Trindade
}

\section{Introdução}

John Dewey (1859-1952) é reconhecido por sua relevância e pioneirismo no campo educacional. Em 1897, com o manifesto intitulado Meu credo pedagógico, inaugura uma vasta reflexão pedagógica que questiona princípios e práticas da escola tradicional. Por essa razão, frequentemente, tem seu nome ligado à Escola Nova e à sua defesa pela renovação do pensamento sobre a Educação. Ainda que Dewey tenha fornecido a base de muitas das ideias desse movimento heterogêneo, iniciado na transição para o século XX, sua pedagogia possui contornos próprios. É possível, inclusive, encontrar críticas do autor aos radicalismos de algumas linhas da Escola Nova, bem como menção às interpretações e apropriações que considerava equivocadas. Assim, é preciso reconhecer sua originalidade e, ainda, a complexidade de sua leitura sobre a sociedade democrática, a qual deriva de tantas das mudanças que ele pensa para a escola. A obra de John Dewey assegura, portanto, seu lugar no atual debate pedagógico.

${ }^{1}$ Este texto deriva da dissertação de mestrado apresentada à Faculdade de Educação da USP em 2009, intitulada Educação, Sociedade e Democracia no pensamento de John Dewey. 
Deweyviveu 92 anos, grande parte deles marcados pela dedicação à produção intelectual e à vida acadêmica. Não se trata, contudo, de um pensador hermético, cujas proposições partam e se destinem aos especialistas: suas reflexões tinham como ponto de partida as questões humanas de seu tempo. Logo, para melhor compreender suas ideias, é preciso resgatar alguns acontecimentos históricos e biográficos que matizam sua produção. Nascido em 1859 nos Estados Unidos, descendia de uma tradicional família que chegou à América em 1630 (portanto, dez anos após o Mayflower atracar no "novo" continente). Como os primeiros imigrantes, esse grupo vinha com a expectativa de fundar uma nova sociedade, com um horizonte maior de liberdade. Os princípios do protestantismo congregacionalista, como a aposta em doutrinas menos fixadas e professadas de modo centralizado, transcendiam a esfera religiosa. Aqui, podemos localizar um primeiro traço do pensamento do autor: a valorização da vida comunitária e da autonomia. Tanto na leitura de Amaral (1990) quanto na de Cunha (2002), a herança familiar de valores participativos e, em seu fundo, democráticos, tiveram peso significativo em sua visão de mundo e no seu apreço pela democracia como tema de sua produção intelectual e de sua prática política e pedagógica.

Denominado por muitos como o "Filósofo da América" (Hickman, 1998, p. ix), Dewey reverencia princípios expressos na Declaração de Independência dos EUA de 1776 e se apoia, em diversas passagens, nos Pais Fundadores de seu país, com destaque ao apreço pelo legado de Thomas Jefferson. O filósofo reconhece essa associação, como quando, defendendo a aliança entre democracia e humanismo, alega que "apenas continua a tradição americana” (Dewey, 1989, p. 97). Por isso seu pensamento e sua história de vida não podem ser apartados do contexto norte-americano em que se produziram. O prestígio, as críticas e a forte identificação de sua figura com o seu país são todos indicativos do êxito que obteve no esforço constante de expressar os conflitos de seu tempo e com eles dialogar. Por essa razão, a herança da tradição democrática de fundação dos EUA é outra característica do 
pensamento de Dewey, ainda que ele a reformule diante das novas configurações histórico-sociais.

Se Dewey parte de questões prementes da vida social, é porque sua filosofia instrumentalista - e aqui temos um terceiro ponto de destaque - valoriza o conhecimento na medida em que este serve à solução de problemas reais do homem (Abbagnano; Visalberghi, 1981, p. 813). Assim, compõem sua agenda de discussão os diversos acontecimentos da primeira metade do século XX, como a ascensão de regimes totalitários de esquerda e de direita na Europa e na Rússia; as duas Guerras Mundiais; a crescente industrialização e urbanização experimentadas em seu país; as condições de trabalho; e o feminismo. Em sua biografia, encontramos exemplos de seu compromisso com o debate público, como a fundação do Sindicado de Professores e da Associação de Professores Universitários (Schmitz, 1980, p. 23), além da participação como presidente na comissão para a defesa de Trotski no julgamento de 1937 (Cunha, 2002, p.23).

É natural que tamanha exposição tenha atraído à sua figura uma série de críticas, por vezes vindas de lados ideológicos opostos. Isso porque as análises de Dewey primam pela complexidade e sustentam abertamente o equilíbrio entre tendências como uma "realização esplendorosa" (Dewey, 1989, p. 76). A busca conciliatória de meio termo se dá, justamente, porque as explicações de fundo radical são consideradas simplificadoras e pouco o satisfazem na compreensão dos sofisticados fenômenos sociais com que se depara.

\section{Fundamentos para compreender a proposta pedagógica de Dewey}

A escola não pode evitar imediatamente os ideais estabelecidos por condições sociais anteriores. Mas ela deve contribuir, através do tipo de disposição intelectual e emocional que forma, para o aprimoramento dessas condições. (Dewey, 1959, p.149-150). ${ }^{2}$

${ }^{2}$ Os excertos extraídos do texto Democracia e educação foram traduzidos tendo 
Para John Dewey, a escola carrega um potencial transformador, ainda que sua atuação sempre se circunscreva em uma dinâmica social que a precede. Todavia, é preciso um rápido alerta: não se trata de uma leitura inocente, que aposte na instituição escolar como imediata e irrestritamente positiva; ao contrário, reconhece a possibilidade dela de se tornar antidemocrática e de minar interesses individuais e sociais. Assim, sua complexa visão da tarefa educativa exige que se compreenda, mesmo que de modo simplificado, como a sociedade democrática é entendida por ele. Pensamos que a ênfase na dimensão pedagógica, apartada de sua reflexão acerca de questões mais amplas, de cunho político, prejudica a compreensão do ideário educativo do autor. A bibliografia educacional tem, por vezes, pinçado o tema da pedagogia, apartando-o do que o envolvia e o explicava, ou seja, daquilo que Dewey pensava sobre a democracia das sociedades adultas. Logo, compreender a relação entre democracia e escola requer dialogar com a perspectiva do autor acerca da construção e consolidação da sociedade democrática.

De partida, Dewey passa por um momento histórico em que claras ameaças à liberdade estão em evidência, como a ascensão de regimes totalitários, marcadamente do nazismo na Alemanha.

No entanto, percebe-se que o risco não é apenas externo: com a lógica capitalista, que intensifica a urbanização e a industrialização, novos desafios se apresentam para que a democracia seja expandida ou mesmo mantida. Entre os fatores internos à sua sociedade, que limitam a experiência democrática, estão a urbanização e industrialização crescentes. O homem da cidade, em sua análise, tem uma vida

por base o original em inglês, disponível na internet, que não contém paginação (Dewey, 1916). A tentativa aqui empreendida é de obter maior fidedignidade à obra original. No entanto, optamos por manter a indicação nas referências da edição em português a fim de servir ao leitor brasileiro que queira recorrer à clássica tradução de Anísio Teixeira e Godofredo Rangel (Dewey, 1959). Essa mesma edição serviu de apoio para a compreensão do texto original e, por essa razão, todas as menções indiretas também a mantém como referência principal. 
comunitária deficiente, acostumando-se a pouco compreender sobre seu entorno e a não se envolver em tomadas de decisão sobre fins comuns. Há excessiva individualização de interesses e valores que, quando misturada à massificação do grande aglomerado de pessoas nas cidades, empobrece as relações sociais em lugar de as incrementar. Por seu turno, a industrialização gera um modelo de organização social e do trabalho que torna os envolvidos fortemente submissos às hierarquias diversas. Tarefas desconexas e repetitivas são executadas, deixando escassas as possibilidades de os trabalhadores se tornarem agentes efetivos de suas ocupações. Resta-lhes uma perspectiva bastante incompleta sobre o próprio processo do qual participam. Ademais, as grandes corporações imprimem um modelo de gestão fortemente hierárquico, tornando a submissão e o baixo envolvimento comportamentos corriqueiros dos trabalhadores (Dewey, 1999). O que o autor identifica, em síntese, são descompassos entre o individuo e a sociedade, um subjugando o outro.

Diante disso, as análises de Dewey apontam para o esfacelamento de ideais de liberdade, igualdade e vida cooperativa: as manifestações antidemocráticas se fazem sentir nos mais variados campos e instituições sociais. Mesmo nos países democráticos, a democracia é apenas nominal: não é vivida efetivamente nas relações políticas e sociais vigentes. Para ele, é difícil compreender porque países com experiências de liberdade e democracia abrem mão desses princípios, ou, no mínimo, limitam-nos a poucas esferas da vida social. Um dos caminhos que encontra para responder a essa questão está no embate da natureza humana com a cultura. Em sua análise, não se trata de determinar se a natureza humana é essencialmente boa ou má. Quaisquer de suas inclinações são fortemente moldadas pela cultura, que é elemento formador de hábitos, disposições e valores. A importância da cultura para o homem é tamanha que o autor a entende como uma segunda natureza, de caráter profundamente arraigado às questões humanas (Dewey, 1989). Dewey compreende que a democracia é uma função da cultura, sendo necessária uma cultura 
livre para sua manutenção e disseminação. É por essa razão que ele entende que liberdade e democracia devem ser tomadas como aposta moral, valores e caminhos deliberadamente escolhidos, e não como fins naturalmente prezados pelo homem. Assim, a democracia surge como uma forma de organização social que possibilita a harmonia entre o indivíduo, pensado como ser social, e a sociedade, que, por seu turno, é uma união orgânica, repleta de vidas que a compõem. Portanto, interesses individuais devem ser traduzidos em função daquilo que também constitui o fim comum e, ao mesmo tempo, a sociedade deve zelar pelas liberdades individuais e pelo pleno desenvolvimento das capacidades de cada um.

Propomos, então, que Dewey trabalha com a seguinte concepção de sociedade democrática:

agrupamento social que, enquanto cuida da realização plena de cada um de seus membros, caminha em direção ao interesse comum, ancorando seus passos em métodos que promovem uma cultura de tolerância e de espírito crítico; com isso, assegura a composição de sua unidade por sujeitos ativos e deliberadamente engajados nos fins de liberdade e emancipação humana. (Trindade, 2009, p.116)

Logo, democracia não é um estado facilmente alcançado. Trata-se de uma realização desafiadora, que só se efetiva por ações cotidianas e valores que as direcionam em todas as esferas da vida social e política de um grupo. Como vimos acima, o período em que Dewey produz seu pensamento corrobora a dificuldade de construção da sociedade democrática. Todavia, se suas reflexões político-sociais trazem um diagnóstico desalentador, sua filosofia da educação surge com o propósito de reconciliação do homem com a construção da experiência democrática ideal. A escola, como agente cultural com potencial transformador, pode, então, favorecer certas disposições, valores e hábitos para dar conta de exigências cada vez mais acentuadas de correção dos rumos da sociedade em direção a uma democracia mais plena. Essa é a pauta do trecho a seguir. 


\section{A pedagogia de John Dewey}

Quando Dewey pensa nas alterações necessárias à educação, o faz para alinhar o trabalho pedagógico com a construção da sociedade democrática e de seus cidadãos. No entanto, reconhece que a escola não é nem a causa principal dos males da sociedade nem a panaceia que os eliminará, pois muitos são os agentes concorrendo na formação da cultura, o que relativiza o papel da educação formal.

A obra do autor é muito vasta, tendo sido composta ao longo de sua extensa vida. Assim, necessariamente, toda tentativa de expressão de suas ideias é um recorte. Aqui, privilegiamos duas obras de Dewey que traduzem alguns dos principais aspectos da sua pedagogia: Meu credo pedagógico (1897) e Democracia e educação (1916). Ainda assim, é preciso eleger alguns pontos para tratar, dado que as análises tangenciam diversos temas. Selecionamos, portanto: a vida da criança e a vida escolar, interesse; jogo e trabalho; matéria e método.

Em Meu credo pedagógico, de 1897, está condensada a substância dos princípios que norteiam sua filosofia da educação. Nesse ensaio, os pensamentos estão expressos em cinco artigos, todos iniciados com a frase "Acredito que". São eles: Que é educação; Que é a escola; $A$ matéria ${ }^{3}$ da educação; $A$ natureza do método; e $A$ escola e o progresso social (Dewey, 1897). O recurso não é uma simples opção de estilo; pela linguagem, Dewey reafirma que determinadas decisões pedagógicas são, em essência, escolhas de caráter ético. Cada uma das cinco partes que compõem o manifesto indicam aquilo que há de matricial em seu pensamento pedagógico: as definições de educação e escola; a relação entre conteúdo e método; e os fins sociais do processo escolar. $\mathrm{O}$ autor inicia o texto debatendo a relação da educação com a partilha do legado cultural da humanidade:

\footnotetext{
${ }^{3}$ No original, o termo é subject-matter, cujo significado mais amplo é assunto, tema. Isso revela um pouco a própria perspectiva de Dewey, de que a matéria da Educação não é essa ou aquela disciplina, mas todo um corpo temático que amplia a experiência do indivíduo.
} 
Através dessa educação inconsciente, o indivíduo gradualmente vem a partilhar os recursos intelectuais e morais que a humanidade conseguiu juntar. Ele se torna um herdeiro desse capital acumulado da civilização. A mais formal e técnica educação no mundo não pode se distanciar sem custos desse processo geral. Ela pode apenas organizálo, ou diferenciá-lo em alguma direção particular. (Dewey, 1897).

$\mathrm{O}$ autor entende que a escola não pode ser pensada apartada da realidade do mundo, pois a educação formal é parte de um processo social mais amplo, que gradualmente torna a criança um dos membros da sociedade. A harmonia indivíduo-sociedade já se lança como desafio àquele que se propõe a educar: "Acredito que a única educação verdadeira vem do estímulo às potencialidades da criança em função das demandas das situações sociais nas quais ela se encontra" (Dewey, 1897). A escola é vista como embrião da vida social e da vida em comunidade, um ambiente simplificado, mas ainda assim repleto de relações sociais. Toda a argumentação é colocada em função dessa dupla atribuição - desenvolver as capacidades individuais, ao mesmo tempo em que se preocupa com o uso social destas: "Se eliminarmos o fator social da criança, ficaremos apenas com uma abstração; se eliminarmos o fator individual da sociedade, resta-nos apenas uma massa inerte e sem vida" (Dewey, 1897). Assim, a formação dos indivíduos só pode ser concebida como desenvolvimento de suas capacidades diante de fins sociais, sem que isso implique, contudo, o exercício de pressão externa e destituída de sentido.

É preciso ressaltar que, se Dewey considera a escola determinante no tipo de sociedade a ser projetada, há também, em seus pressupostos, a orientação para uma educação que tenha sentido em si mesma. Portanto, quando reconhece a organização escolar como uma comunidade, a educação não se restringe à preparação exclusiva de um futuro distante, mas passa a compor a experiência vital da criança. $\mathrm{O}$ autor não nega que a educação tenha função no preparo para a vida futura, mas problematiza como fazê-lo, antecipando uma questão que 
é constante alvo de reflexão pedagógica: "com o advento da democracia e das condições industriais modernas, é impossível predizer de forma definitiva e precisa o que a civilização será daqui a vinte anos. Assim, é impossível preparar a criança para qualquer conjunto preciso de condições" (Dewey, 1897).

Dewey é bastante reconhecido por atribuir valor próprio à infância. Daí um de seus mais importantes princípios estar expresso na frase: "Acredito, finalmente, que a educação deve ser concebida como uma reconstrução contínua da experiência; que o processo e o objetivo da educação são uma e a mesma coisa” (Dewey, 1897). Aqui, vemos que não existe hierarquia entre meio e fim. A ideia de que a educação é vida pulsante, com valor próprio, é importantíssima em seu pensamento e vai direcionar suas proposições acerca da relação entre matéria e método, como veremos adiante.

A criança tem na escola a manifestação específica de sua vida social, que influencia na consolidação de disposições, hábitos e valores. Em sua concepção de democracia, John Dewey entrelaça objetivos e fins com o modo como os atingimos, na medida em que não se chega à sociedade democrática sem se valer de métodos democráticos: onde prevalecem formas antidemocráticas, o horizonte da liberdade está distante (Dewey, 1989). Se, nas diversas esferas da sociedade, os fins só devem ser alcançados por meio de meios válidos, na educação não é diferente. Dewey estabelece que os meios da educação devem considerar o presente, a experiência e o interesse do aluno e do grupo em destaque. Em sua vasta produção especificamente voltada à pedagogia, o autor propõe métodos e práticas com a finalidade de assegurar um processo dotado de sentido para a criança e coerente com o projeto social. Para o autor, é crítica a situação corrente, marcadamente nas relações de trabalho, em que ações desprovidas de sentido são levadas a cabo sem que o objetivo seja sequer vislumbrado pelo agente. Isso seria mais difícil se, desde crianças, buscássemos conhecer mais sobre o que fazemos e o porquê.

Também é esclarecedora a diferença entre educação e escola, em 
que a primeira surge como processo social e a segunda como instituição social. Assim, a escola deve se constituir como a instituição mais bem preparada para formar o aluno, tanto na participação do saber acumulado quanto no desenvolvimento de suas capacidades próprias. Dewey identifica diretamente dois tipos de conteúdo que, em termos atuais, podemos traduzir como conteúdo conceitual (conhecimento acumulado) e procedimental (potencialidades, habilidades); ao mesmo tempo, uma vez que coloca como diretriz o uso social das capacidades, inclui também o campo ético. $\mathrm{O}$ que hoje é tido como conteúdo atitudinal, a dimensão formativa de valores e atitudes, fica mais evidente em outras passagens, como quando descreve a tarefa da escola de continuar e ampliar a educação moral iniciada em casa (Dewey, 1897). É fundamental uma postura ativa na promoção de uma cultura livre, que viabilize a sociedade democrática projetada (Dewey, 1989). A escola se insere nesse contexto como agente cultural e seu escopo transcende as preocupações mais diretas: ela precisa ser pensada e praticada em função do modelo social desejado.

A escola e a educação devem, portanto, ser pensadas, estruturadas e vivenciadas no sentido da promoção de uma cultura de liberdade e democracia deliberadamente escolhida. Selecionar os elementos que vão influenciar a formação da criança é, justamente, atentar para a composição da segunda natureza do indivíduo em direção ao ideal social projetado. Como a questão da liberdade não se esgota na esfera política, é preciso se fazer sentir em todas as instituições culturais. Por essa razão, os meios pelos quais alcançamos os objetivos pedagógicos são tão essenciais: não é possível formar indivíduos e sociedades livres por intermédio de uma prática escolar castradora.

A cultura promove pensamentos, valores e ações, sendo capaz de sustentar ou de minar a democracia. O papel do professor também é melhor compreendido quando colocado em função desta perspectiva: ele é o membro da comunidade escolar que se responsabiliza por "selecionar as influências que afetarão a criança e auxiliá-la a responder adequadamente a essas influências” (Dewey, 1897). Assim, não se trata 
da imposição de conteúdos ou de hábitos, mas justamente do trabalho de condução das interações entre a natureza humana e a cultura em direção ao ideal democrático. Podemos dizer que o professor é um importante agente na composição dessa segunda natureza, que precisa ser construída para favorecer a sociedade democrática. Como vimos, a análise de Dewey (1989) não é inocente: identifica uma variedade de instituições formadoras da cultura, competindo na promoção de interesses e visões de mundo. Parece-nos fundamental o fato de Dewey não automatizar os valores e fins que a escola dissemina, podendo ela também promover hostilidade à democracia. No excerto abaixo, o autor destaca sua possibilidade totalizadora pelo exemplo alemão:

Suas escolas eram tão eficientes que o país tinha a mais baixa taxa de analfabetismo do mundo e as pesquisas acadêmicas e científicas de suas universidades eram conhecidas por todo o mundo civilizado [...]. Entretanto, as escolas alemãs elementares forneceram o alimento intelectual para a propaganda totalitária e as escolas superiores constituíram os centros de reação contra a República Alemã. (Dewey, 1989, p. 38)

A reflexão nos prova que a escola não é intrinsecamente positiva para a manutenção da democracia - e isso não acontece por conta de eventuais ineficiências na transmissão de conteúdos, como na escola da Alemanha acima relatada. Fundamentalmente, reside em seus métodos e práticas cotidianas a capacidade de favorecer uma cultura emancipadora ou antidemocrática. Assim, a aquisição dos saberes escolares é significada pelo método empregado e pelos princípios que ele expressa, à medida que gradativamente fomentam procedimentos, posturas, atitudes e valores, compondo uma dada cultura. Vale marcar que toda a preocupação de Dewey com o método não deve ser lida como descaso quanto ao conteúdo. Como vimos, o autor parte da ideia de que a educação se responsabiliza pela transmissão do legado cultural da humanidade. 
Podemos entender que partilhar saberes e valores tem duas facetas para Dewey. A primeira, de caráter predominantemente social, consiste na composição de um repertório comum entre os indivíduos que possibilite a vida em conjunto. Já a outra dimensão se volta mais para o indivíduo, cuja participação ativa na comunidade depende de não ficar à margem de conteúdos e valores socialmente reconhecidos. Mais uma vez, o equilíbrio indivíduo-sociedade se expressa nos princípios pedagógicos do autor. A dupla atribuição do professor está marcada no compromisso com o desenvolvimento de cada criança e, ao mesmo tempo, na sua formação para a vida social, que dependem igualmente da construção desse denominador comum entre os homens.

O método para John Dewey está sempre na dependência da matéria. Isso quer dizer que não pode ser pensado de maneira dualista, pois ele é o meio pelo qual se trabalha de maneira proveitosa a matéria, conectando-a com a experiência e levando-a a outro patamar. A matéria, por sua vez, é concebida como assuntos intrinsecamente relacionados à vida social, porque a expressam (caso da literatura e das artes) e porque a constroem ou explicam (a exemplo da história e das ciências): "Se educação é vida, toda vida tem, de partida, um aspecto científico, um aspecto de arte e cultura e um aspecto de comunicação" (Dewey, 1897). Quando a matéria é posta para o aluno sob essa ótica, ela se preenche de significação e mais facilmente começa a interagir com a experiência passada.

Ao trabalhar os conceitos de método e matéria, Dewey observa que essa divisão tem uma função operatória, analítica, isto é, separa-se em categorias distintas, o que é, na realidade, um mesmo fenômeno. Logo, o método se apresenta como dependente da matéria: "Método significa o arranjo da matéria que torna o seu uso mais eficaz. Nunca será método alguma coisa externa à matéria” (Dewey, 1959, p.182). Esse trecho invalida uma crítica bastante difundida de que, nos fundamentos da Escola Nova, defende-se o esvaziamento do conteúdo em função do método. $\mathrm{O}$ autor coloca o domínio da matéria como condição fundamental para o trabalho do professor, enquanto o 
método se apresenta como diferencial para um processo pedagógico adequado que traga os resultados esperados.

Para Dewey (1897), a criança precisa passar pela gradual sensação de pertença a um grupo, que terá sua forma máxima manifesta em uma consciência social futura. Se o ser humano não se basta a si mesmo, ou seja, se não é determinado pela sua própria individualidade, à sociedade, por outro lado, também é imprescindível considerar o fator individual. Em Meu credo pedagógico, o autor percebe que, sem esse componente, ela se converte em uma massa inerte e morta: o desenvolvimento de capacidades individuais (sem esquecer seus usos sociais) constitui uma das respostas ao crescente fenômeno de massificação. Dewey debruçase, por exemplo, sobre as mudanças trazidas pelas novas tecnologias da época, que tornam possível se informar sobre eventos dispersos pelo mundo. A exposição a esses dados de forma alguma se traduz em maior compreensão do indivíduo acerca dos processos complexos que envolvem a sociedade. Essas condições prejudicam efetivamente o espírito crítico:

há muita informação sobre que o juízo não é chamado a responder, e que, mesmo se o quisesse fazer, não seria capaz de agir efetivamente, tão dispersivo é o material sobre que seria chamado a se aplicar. A pessoa média hoje está rodeada de bens intelectuais pré-fabricados, a exemplo de alimentos, artigos e toda espécie de instrumentos manufaturados. Não tem a participação pessoal na criação de seus bens intelectuais ou materiais que seus antepassados tiveram. Estes, consequentemente, conheciam melhor aquilo de que se ocupavam, embora soubessem infinitamente menos sobre o que o mundo em geral estivesse fazendo. (Dewey, 1989, p. 41).

As atividades escolares, quando pensadas em função do interesse e da experiência do aluno, podem servir de resistência à dinâmica de submissão do homem à máquina: 
Se a massa dos seres humanos encontra usualmente em suas ocupações industriais nada além dos males que devem ser suportados pelo bem da manutenção de sua existência, a culpa não é das ocupações, mas das condições em que são levadas a cabo. O contínuo aumento de importância dos fatores econômicos na vida contemporânea torna ainda mais necessário que seu conteúdo científico e valor social sejam revelados pela educação. Pois nas escolas, ocupações não são levadas pelo lucro pecuniário, mas por seu próprio conteúdo. Livre de associações extrínsecas e das pressões para se ganhar o salário, elas fornecem tipos de experiência que são intrinsecamente valiosas; são verdadeiramente libertadoras em qualidade. (Dewey, 1959, p. 220).

O excerto pertence à discussão levantada em Democracia e educação a respeito do jogo e do trabalho. Julgamos marcante que, em meio à sua explanação pedagógica, John Dewey encontre espaço para manifestar sua crítica à sociedade. $\mathrm{O}$ jogo e o trabalho são aqui entendidos como um espaço formativo que, ao proporcionar uma experiência mais plena ao aluno, fomenta o resgate da autoria do homem em suas ações. Isso se dá pelo fato de o jogo e o trabalho possibilitarem um "aprender como fazer as coisas" (Dewey, 1959, p. 215), isto é, eles desenvolvem ocupações. Estas são proveitosas enquanto "busca ativa a fins sociais" (Dewey, 1959, p. 216). Tendo por base o mapeamento da concepção de democracia de Dewey, o termo ativo ganha contornos mais definidos: não se trata de atividade expressa em qualquer tipo de dinâmica exterior, mas como aquilo que é o oposto do passivo. Ativo implica devolver ao indivíduo a possibilidade e responsabilidade de intervir, de conduzir os negócios humanos, o que só se dá quando se conhece na íntegra o resultado de sua ocupação. $\mathrm{O}$ fim permite que a atividade tenha propósito por si mesma e que o conhecimento seja fruto da necessidade da ação, resultando no que o autor denomina de o inteligente uso das coisas.

Um dos objetivos da educação é resgatar o foco das ocupações humanas com o fim social naquilo que é de interesse da comunidade. 
A compreensão da divisão social do trabalho é base para a formação política e econômica do indivíduo. Isso se faz ainda mais premente quando se visualizam, no estado corrente das coisas, as ambições particulares destruindo o ideal democrático:

Nossas condições econômicas ainda relegam muitos homens a um estado servil. Consequentemente, não é liberal a inteligência daqueles no controle da situação prática. Ao invés de atuar livremente pela submissão do mundo a fins humanos, dedica-se à manipulação de outros homens para fins que são inumanos, na medida em que são exclusivos. (Dewey, 1959, p.149).

Como se vê, toda a crítica de Dewey aos excessos do capitalismo, da industrialização e das novas configurações do trabalho passa pelo marcado incômodo que ele sente diante da (aparente) impotência do homem para intervir no seu próprio rumo. $\mathrm{O}$ cenário é agravado visto que isso sequer é percebido por cada um que se encontra submerso nos mares das forças impessoais, fragmentado pela própria atuação em atividades apartadas de seu resultado final. $\mathrm{O}$ interesse se configura como conceito central na tentativa de reverter essa aceitação de experiências alienantes. $\mathrm{O}$ termo, contudo, pode assumir muitas acepções, o que exige demarcá-lo melhor dentro da ótica de Dewey.

Para o autor, interesse traduz a ideia daquela atitude que preza pelos efeitos da ação, tentando assegurar os melhores e evitar os piores (Dewey, 1959, p. 136), expressando a dimensão de "ser ativo, que participa das consequências ao invés de ficar de fora delas" (Dewey, 1959, p. 137). O sujeito interessado é aquele que reage diante da situação, porque quer - de alguma forma e em algum nível determinar o curso dela. Portanto, é aquele que age inteligentemente em direção a um objetivo. Diante disso, podemos sintetizar interesse como a intenção de influenciar o resultado de uma ação e que póe, assim, a pessoa em movimento.

Logo, a tarefa educativa pautada pela concepção de interesse 
consiste em "descobrir objetos e modos de ação, que estão conectados com capacidades presentes [... visando] pôr em movimento uma atividade e mantê-la de maneira consistente e contínua" (Dewey, 1959 , p. 139). Dewey condena tanto aqueles que assumem o interesse na pedagogia como o uso de artifícios para fazer parecer prazeroso aquilo que se deseja ensinar quanto os que, ao condená-lo, tornam as coisas arbitrárias e estranhas ao aluno. Se o interesse na pedagogia de Dewey não resulta na solução vazia de tornar aparentemente atrativas as atividades escolares, tampouco quer dizer restringir-se àquilo que interessa ao aluno (ou, como vimos, à experiência que já possui). Justamente para enfatizar esse último aspecto, Dewey recorre à própria etimologia da palavra, que sugere aquilo que une dois pontos; nesse sentido, "as capacidades atuais do aluno são o estágio inicial; o objetivo do professor representa o limite remoto”(Dewey, 1959, p. 139). Por essa passagem, o autor evidencia que o conceito representa marcadamente a importância de se mobilizar aquilo que o indivíduo já sabe, aquilo que pertence à sua experiência. É ponto de partida, não de chegada. A perspectiva do interesse aprofunda a compreensão do apelo ao jogo e ao trabalho na concepção pedagógica de Dewey como manifestações que relacionam a criança com suas experiências e, simultaneamente, permitem a elas enxergar o resultado completo de uma atividade.

Logo, pela leitura de Dewey, entendemos que o processo pedagógico que desconsidera o interesse contribui para o surgimento do sujeito acrítico e propício à alienação. Isso acontece na medida em que o indivíduo se acostumou, ao longo de sua vida escolar, a empreender atividades cujos objetivos e resultados (ou consequências) ele desconhece. A perda da noção entre a atividade e seu fim implica, por sua vez, uma postura passiva, já que nenhuma tentativa é feita para influenciar o resultado a ser atingido. Uma escola que abdica de conectar a experiência do aluno com aquilo que ela (e a sociedade) elege como relevante para ele, que inviabiliza o diálogo entre as matérias por estarem radicalmente segregadas, que se furta a explicitar os objetivos efetivos das atividades é uma instituição social com 
cultura antidemocrática. Seu resultado social é a pronta aceitação pelo indivíduo da condição de simples peça de um mecanismo que ele ignora nos sentidos mais amplos. Não é de se estranhar que a sociedade se converta em um aglomerado desconexo quando a dimensão individual - marcada pela ação protagonista - está ausente. E o protagonismo só se manifesta por meio do interesse, que funciona como acionador de um processo.

Como vimos, a massificação tira do indivíduo sua possibilidade de ação e reflexão, esfacelando o espírito comunitário. Analogamente, na perspectiva da educação, quando há perda do sentido da comunidade escolar, muitos problemas se sucedem:

Acredito que muito da educação de hoje falha porque negligencia esse princípio fundamental da escola como uma forma de vida comunitária. Ela concebe a escola como um lugar onde certas informações são dadas, onde certas lições devem ser aprendidas, ou onde certos hábitos devem ser formados. Concebe-se o valor destes pesadamente assentado num futuro remoto; a criança precisa fazer essas coisas pelo bem de alguma outra coisa que ela irá fazer; são mera preparação. Consequentemente, não se tornam parte da experiência de vida da criança, logo não são verdadeiramente educativas. (Dewey, 1897).

O trecho acima mostra como, na perspectiva do autor, são combinadas as ideias de educação como um processo social e sua valorização intrínseca como experiência do presente, significativa para o indivíduo e para o grupo. Isso quer dizer que, por conta de sua expressão como manifestação da vida comunitária, a educação se preenche de relevância própria e, ao mesmo tempo, contribui para a preparação do indivíduo em direção ao ingresso futuro da sociedade democrática, por estar habituado à dinâmica coletiva.

A primeira função do órgão social que chamamos escola é proporcionar um ambiente simplificado. Ela seleciona as características mais 
fundamentais e passíveis de resposta por parte dos jovens. Então estabelece uma ordem progressiva, usando os fatores primeiramente adquiridos como meios para compreender o que é mais complicado. (Dewey, 1959, p. 21).

De acordo com Dewey, o método tem um componente geral que se aplica às distintas situações e que é fruto do acúmulo de experiências e saberes humanos; e uma faceta individual, por conta de existir um "caminho de abordar as coisas" (Dewey, 1959, p. 185) próprio a cada um. Isso torna o método, em alguma medida, individualizado, atribuindo importância ainda maior à consideração das experiências dos alunos no processo pedagógico. Por conta dessa dimensão, o método passa a ter como possibilidade intrínseca a sua flexibilização. Também o método democrático deve ter essa possibilidade, visto que nunca deve ser assumido como autômato, tendo sempre de acolher movimentos de autorrevisão. Dewey (1989) defende a contínua avaliação dos mecanismos e das instituições que compõem a sociedade democrática, a exemplo da Constituição americana, tão frequentemente desconsiderada como produção humana, datada, falível e, portanto, passível de aprimoramentos.

O autor trabalha com noções acerca do controle social e da liberdade nas relações escolares dentro de uma perspectiva microcósmica. Para o pensador, o exercício da liberdade não implica ausência de controle externo. Este se mostra inevitável, até necessário, na organização da vida social. Porém, na sua forma, deve ser o mais natural possível, ou seja, legitimado pela razoabilidade das normas. Para Dewey (1998), as relações sociais podem ser comparadas a um jogo, em que há regras inerentes que zelam por um espírito cooperativo entre os participantes. Afinal, elas são criadas internamente e perpetuadas pela tradição visando a um bem comum. Por essa razão, o indivíduo não se sente submetido a um controle social, e, pelo contrário, apenas contestará as situações em que houver ruptura dos contratos tacitamente firmados. 
Se no jogo, intrinsecamente competitivo, há essa dimensão cooperativa, na família e no ambiente escolar a característica se acentua, principalmente porque existem objetivos comuns ao grupo. Da mesma maneira, regras de conduta autênticas devem idealmente ser estabelecidas em sala de aula com o propósito de diminuir os conflitos de convivência.

Dewey (1998) acredita que o controle dos alunos pode ocorrer de forma mais natural, quando se efetua por intermédio da própria atividade escolar. A escola tradicional procura manter a ordem por meio da imposição da vontade do professor, visto mais como um chefe. Em contrapartida, o educador da escola progressista, ao lançar mão da autoridade, deve fazê-lo de maneira justa, visando ao interesse coletivo, representando figura análoga a de um líder. Podemos notar que a essa concepção aplicam-se os princípios norteadores da democracia, em que a vontade coletiva impõe-se, frequentemente, sobre os interesses particulares do indivíduo.

A detecção das demandas do grupo social configurado pelos alunos só pode ser realizada com precisão pelo professor por meio de um conhecimento profundo tanto da matéria quanto dos indivíduos que o integram (Dewey, 1998). A atividade essencial de planejamento para assegurar o controle social só pode ser devidamente realizada em posse desse embasamento. $\mathrm{O}$ planejamento, de acordo com o autor, deve prever a existência de exceções - como alunos rebeldes ou excessivamente passivos -, mas nunca se calcar nelas. Também, seguindo o princípio da liberdade, não pode ser imposto ao aluno. Assim, o planejamento demonstra duas dimensões: uma firme, em que se garante a continuidade do trabalho escolar; e outra flexível, que viabiliza a interação e o aproveitamento das experiências individuais dos alunos.

Outro conceito tratado com ênfase por Dewey (1998) é a liberdade de inteligência, que constitui a própria finalidade da educação. Como tipo de liberdade-fim, deve efetuar-se mediante a liberdade-meio, que se compõe da manifestação externa, física e de 
movimento. "Este lado exterior e físico da atividade não pode ser separado do seu lado interno, da liberdade de pensamento, desejo e propósito" (Dewey, 1998, p. 69). O movimento, tão restrito no modelo da escola tradicional, é importante por duas razões principais. Primeiro, porque na liberdade de movimento, o professor tem a oportunidade de conhecer o ser, e não o parecer. Quando o aluno se encontra em uma situação de restrição exterior, assume uma imagem de "uniformidade artificial" (Dewey, 1998, p. 71) que não condiz com a sua natureza mais sincera. Segundo, porque a mobilidade é um recurso de auxílio à aprendizagem. Para o pensador, a aprendizagem se dá no momento da atividade, enquanto a reflexão silenciosa é breve e tem por propósito organizar e consolidar o conteúdo. E é justamente a liberdade da manifestação do corpo que permite criar a liberdade maior e posterior, de domínio - quando conveniente desse mesmo corpo. Mais uma vez, trata-se do profundo incômodo de Dewey com as dicotomias simplificadoras da vida humana, que obscurecem a percepção tanto sobre os fenômenos educativos quanto sobre os sociais como um todo.

Diante dessa perspectiva da ação como essencial no processo pedagógico, podemos equivocadamente entender que Dewey valida a ação impulsiva. Porém, para ele, a liberdade consiste no autodomínio, bem distante do "fazer o que se quer". Agir conforme os impulsos significa se transformar em escravo deles, distante do ideal emancipatório da educação. Para atingir o autodomínio, o indivíduo deve inibir a ação imediata provocada por um impulso e convertêlo em propósito. Alcança-se isso por meio da reflexão, evocada pela experiência (própria ou em forma de conselho). Chega-se, assim, a um plano de ação que considera as próprias consequências e permite ao indivíduo tomar uma decisão livre.

Dentro desse contexto, parece-nos importante debater a concepção de disciplina na pedagogia de Dewey. Como vimos, para o autor, disciplina não é aquele silêncio artificial durante as atividades escolares. Ele recorda que as situações correntes da vida são, na maior 
parte das vezes, espaços de interação, e que não se vê, nessas ocasiões, o ambiente controladamente quieto da sala de aula. Segundo Dewey (1959), disciplina é ter resolução em direção a um objetivo estabelecido e calculado em função das consequências implicadas. O silêncio só pode ser positivo quando, em algumas ocasiões, a própria tarefa que se empenha demanda por ele - daí é um tipo distinto de silêncio, natural e não imposto. Logo, a disciplina deve ser fruto do processo dinâmico da educação, como exigência dessa forma de vida: "Acredito que a criança deva ser estimulada e controlada em seu trabalho através da vida da comunidade" (Dewey, 1897). Se a disciplina e o controle derivarem do autoritarismo do professor, corre-se o risco de se tornarem apenas uma manifestação aparente de concentração, levando a uma postura desprovida de inteligência e atitude por parte do aluno. Tendo por princípio sua concepção de cultura, entendemos que, ao se habituar a essa "pseudocompenetração", o indivíduo se acostuma com a execução de atividades alienantes, sem esboçar o menor sinal de contestação. Essas considerações acerca da disciplina têm o intuito de tornar a postura exterior um reflexo da disposição de espírito:

Uma pessoa que é exercitada a considerar suas ações, a tomá-las deliberadamente, é nessa medida disciplinada. Adicione a essa habilidade um poder de resistir em um curso inteligentemente escolhido em face à distração, confusão e dificuldade, e você tem a essência da disciplina. (Dewey, 1959, p. 141).

Dewey empenhou intensos esforços intelectuais para expressar a importância da educação e da escola no desenvolvimento social. $\mathrm{O}$ próprio título Democracia e educação já lança o tom da discussão de uma obra que, apesar de se voltar a detalhamentos de aspectos pedagógicos de sua filosofia da educação, procura fazê-lo ponderando a relação com a construção da democracia. Também o último artigo de $M e u$ credo pedagógico constitui uma manifestação, ainda que embrionária, de sua aposta na educação como promotora das mudanças. Como discutimos 
há pouco, não se trata de uma visão romântica que naturaliza o progresso como efeito educativo. Ao contrário: é justamente por entender isso que o autor vê a necessidade de se pormenorizar a discussão pedagógica investigando os caminhos que garantam a experiência social democrática.

Acredito que a educação é o método fundamental de progresso social e de reforma. Acredito que todas as reformas que se ancoram simplesmente na promulgação de leis, ou na ameaça de certas penalidades, ou ainda em mudanças por arranjos mecânicos ou exteriores, são transitórias e fúteis. (Dewey, 1897).

A condução da prática pedagógica corrente tem, sob a lente analítica da revisão de Dewey, favorecido a formação de indivíduos desacostumados à reflexão crítica e ao livre pensar. Aos poucos, a curiosidade natural é substituída por uma aceitação das informações prontas, reveladas. Sabemos que parte significativa de sua obra procurou trabalhar essa dimensão, tanto pelo próprio foco na formação do homem como indivíduo quanto pelo viés da demanda social por sujeitos reflexivos e ativos. John Dewey buscava, a cada novo texto sobre educação, propor rupturas e reformulações nos princípios pedagógicos que resultassem em um tipo distinto de ser humano durante o processo educativo e ao final dele.

O espaço da educação é, por excelência, de interação entre indivíduo e sociedade, entre natureza humana e cultura, por isso a sua dimensão formal só pode ser entendida como parte de um processo mais amplo. Para ser verdadeira, ela precisa mobilizar as exigências concretas das crianças na lapidação de suas capacidades; precisa também, em uma perspectiva macrossocial, considerar as demandas da sociedade para uma harmônica integração do indivíduo no grupo. Tal perspectiva não é a simplificadora adaptação à civilização, que aprisiona o homem em um estado definido de coisas: trata-se de uma participação ativa na conquista da democracia e no constante zelo que 
sua manutenção exige. A escolarização é, pois, o momento oportuno de preparo e exercício primeiro da experiência democrática.

Em síntese, vale ter em mente dois elementos-chave derivados de sua visão de sociedade democrática e que apoiaram a interpretação do pensamento pedagógico do autor. Primeiramente, destacamos o tipo específico de individualismo defendido por Dewey. Pensar a escola e a educação será, então, sempre uma função que busca equilibrar indivíduo e sociedade, ou seja, que quer promover os interesses e habilidades de cada pessoa sem que isso resulte na dilapidação do projeto social comum. Podemos dizer que a busca pela harmonia do indivíduo com a sociedade é tanto um fim da educação de John Dewey quanto um meio sem o qual o fim se torna inalcançável. $\mathrm{O}$ segundo ponto que norteia as reflexões abaixo se relaciona com o papel atribuído pelo autor à cultura. Quando a sociedade democrática entra em perspectiva, os valores que a ancoram precisam ser deliberadamente promovidos pelas mais distintas instituições sociais. Por essa razão, a escola proposta por Dewey precisa fomentar o espírito democrático, o que exige que ela, como instituição, não exerça práticas antidemocráticas. Mais uma vez, trata-se da democracia como fim e como método, sem o qual não é possível sustentar conquistas e expandi-las.

\section{Breve nota sobre a atualidade de seu pensamento}

O alerta de John Dewey quanto à fragilidade das sociedades democráticas continua na ordem do dia. Como primeiro imperativo, temos de soltar os grilhões da ilusão de vivermos em um estado democrático pleno e consolidado. Essa clareza exigir-nos-á pensar acerca dos princípios e das práticas sociais que favorecem a liberdade e a democracia, trazendo condições mais justas para a existência humana. Por sua vez, impõe à educação a difícil missão de contribuir para a criação da sociedade democrática. Ela deve formar indivíduos capazes de partilhar significados e valores na vida social. A criança precisa ser preparada criticamente para uma sociedade complexa, cuja 
tendência ao império de forças impessoais é crescente. $\mathrm{O}$ meio para se conseguir isso, contudo, não consiste na antecipação de dilemas sociais para os quais a criança ainda não está preparada. Sobretudo, tratase de oferecer condições para seu pleno desenvolvimento intelectual, corporal, emocional e moral. Cada movimento nesse sentido deve ser balizado pelas exigências que a criação de uma sociedade democrática impõe, expressas na busca pela harmonia indivíduo-sociedade.

Dewey vê no homem comum, por conta de seu caráter avesso à radicalização, o esteio da democracia. Parece-nos que o autor despendeu a maior parte de seu engajamento reflexivo tentando descobrir caminhos para a educação, justamente pela influência que ela dirige à sociedade. Ao compreender a democracia como uma questão posta no campo da ética, Dewey chama o homem a responsabilizarse pelo seu caminho. A educação é o chamado daqueles que se responsabilizam pela formação desse homem comum no cuidado com o desenvolvimento de cada um de seus integrantes.

Cerca de vinte anos depois da publicação de seu credo, Dewey estende a toda a escola a função antes atribuída ao professor de escolher e encaminhar as influências que atingem os alunos. Em sua filosofia política, o autor mostra que as relações sociais estão cada vez mais imbricadas e obscurecidas. Forças impessoais, principalmente no âmbito da economia, parecem ditar os rumos da associação humana, impossibilitando sua alteração pela ação individual (Dewey, 1989, 1999). E essa crescente complexidade social tem implicações pedagógicas. Dewey defende que o ensino deve considerar a forma como se dá o desenvolvimento da criança: partir do simples para o mais complexo; do conhecido para o novo; da experiência para sua reconstrução. A escola como simplificação da sociedade obedece a essa lógica. Tempos depois, as proposições de $\mathrm{Piaget}^{4}$, cuja psicologia do desenvolvimento também afirma que o pensamento parte do concreto em direção à abstração, serão colocadas sob a lógica da ciência. Julgamos

\footnotetext{
${ }^{4}$ Piaget nasceu em 1896, um ano antes da publicação de Meu credo pedagógico; e ainda era estudante quando Dewey escreveu Democracia e educação.
} 
pertinente sublinhar que Dewey pensa as etapas de desenvolvimento pelo viés filosófico (ou até como uma crença). $\mathrm{O}$ autor defende que seguir a sequência respeita o caminho natural da criança, mas o faz sem pretensão científica. Tal diferença é, em nosso ponto de vista, bastante significativa para a Pedagogia, porque as ideias de Dewey se apresentam mais prontamente abertas ao debate e à contestação. Apesar de a ciência sempre incorporar em sua dinâmica a crítica a seus enunciados, sua fala incorpora uma certa autoridade que permite somente aos especialistas em um determinado fenômeno questionála. Na reflexão filosófica tradicional, não há exigências desse gênero, concedendo a todos que se debrucem a interpretar um pensamento a possibilidade de se filiar a ele ou de rejeitá-lo. Assim, Dewey se coloca como importante figura da produção autêntica do campo pedagógico, cujas teorias e práticas devem estar prontas para um intenso diálogo e contínuo aperfeiçoamento. Nesse sentido, discordar de uma das crenças de Dewey não implica condenar as demais ideias do autor - não devemos conceber sua obra como um bolsão paradigmático. Não se trata de desconsiderar as pistas de outras ciências, como a Psicologia, mas de não as assumir como o único estofo do pensamento sobre a educação. Portanto, a rejeição da força da ciência para ancorar um argumento possibilita que sua obra dialogue com os leitores de diferentes épocas, tornando-se simultaneamente mais aberta à revisão e, por isso mesmo, mais perene.

\section{Referências}

ABBAGNANO, N.; VISALBERGHI, A. John Dewey e a "escola progressiva" americana. In: . História da Pedagogia, v. 4. Lisboa: Livros Horizonte, 1981, p. 813-827.

AMARAL, Maria Nazaré de Camargo Pacheco. Derwey: filosofia e experiência democrática. São Paulo: Perspectiva/EDUSP, 1990. (Coleção Debates). CUNHA, Marcus Vinícius da. John Dewey: uma filosofia para educadores em sala de aula. 4. ed. Petrópolis: Vozes, 2002. (Coleção Educação e conhecimento). 
DEWEY, John. My pedagogic creed. School Journal, v. 54, jan. 1897, p. 77-80. Disponível em: <http://dewey.pragmatism.org/creed.htm>. Acesso em: jul. 2005.

DEWEY, John. Democracy and education. New York: Institute for Learning Technologies (ILT), 1916. Disponível em: <http://www.ilt.columbia.edu/Publications/dewey.html>. Acesso em: nov. 2008.

DEWEY, John. Democracia e Educação: introdução à Filosofia da Educação. Trad. Godofredo Rangel e Anísio Teixeira. São Paulo: Cia Editora Nacional, 1959.

DEWEY, John. Freedom and culture. New York: Prometheus Books, 1989.

DEWEY, John. Experience and education. Indianapolis: Kappa Delta Pi, 1998.

DEWEY, John. Individualism old and new. New York: Prometheus Books, 1999.

HICKMAN, Larry A. (Ed.). Reading Dewey: interpretations for a postmodern generation. Bloomington/Indianapolis: Indiana University Press, 1998.

SCHMITZ, Egídio Francisco. O pragmatismo de Dewey na educação: esboço de uma filosofia da educação. Rio de Janeiro: Livros Técnicos e Científicos, 1980.

TRINDADE, Christiane Coutheux. Educaşão, sociedade e democracia no pensamento de John Dewwey. 2009. Dissertação (Mestrado em Educação). Faculdade de Educação da Universidade de São Paulo, São Paulo, 2009. 